\title{
THREE MONKEYS. I AM FATHER
}

\author{
WILL BAKER
}

\section{Tsitsi, the Faithful}

The first two came quick as squirrels, tails questioning, their faces small and old as time. Carlos and cumado hissed, threshed a branch, teased until they skittered here, there, through leaves and crisscross of vines.

Now they are just above. Cunado nooks an arrow, draws, and with a sudden sigh it slides through air, through the little body. It excites her. Her legs jerk and anxious fingers fondle the hard shaft, an awkward pendant she drags this way and that.

Frantically he scurries up, down, squeaks, plucks at her shoulder:

Came! Came! We must away!

Cunado's eyes and teeth glisten. Again he nooks, draws, releases. The arrow rises rapid as a swallow, slows through flesh, halts, halfway red. He pinwheels from branch to branch, forgetting her now as she has forgotten him, and the hunters hoot at this slapstick agony, this silly tale of fidelity.

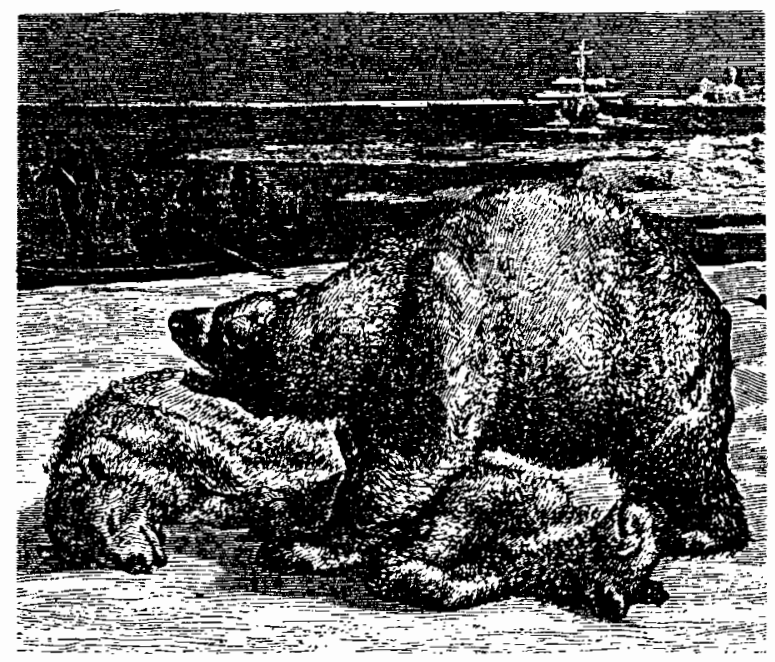

\section{Oshtero, the spider}

She was all afternoon squatted on Cunado's back, the vine rope under her long black arms, knees lashed to elloows. She seemed to nod, and gaped at me with a stupid lip drooling blood. Alive she was an angular, sloping shadow through green caverns. In death she did not curl but came down like syrup through the trees.

Once the vines gave way at a joint so Cunado did a new knot hiking an arm high in farewell gesture. She preserved it so until sundown when we lay them all on a mat by the fire. There she seemed to gaze straight up to heaven and raise that hand to the next evolutionary rung.

Carlos' wife puts water to boil. A child brings a candle from the hut. The blade goes brisk back and forth across a flat rock. By arm and leg the carcass is upended, head down in the steaming pot, then out; from dark fur the wife begins to peel an ivory doll's skull. Next pathetic shoulders, a sunken chest. By trick of fire and candlelight she seems to duck, embarrassed, before she goes ass up into the kettle again.

By the men's fire I am joshed, offered a tiny forearm already crisp. They have noted the heavy pelt on my chest, the fuzz at my cuffs, the shadow on my chin. Here is your son, your daughter, they say, running a brown hand over my wrist. Their faces are smooth as river stones. Their eyes are deep and full of light. His son! they say. It is his son! Then they only eat and laugh, with nothing in between. 